\title{
Bacterial contamination of platelet concentrates
}

\section{Introduction}

Implementation of antibody screening followed by nucleic acid amplification techniques in blood donor screenings have significantly reduced transfusion related viral transfusion over the last several years but bacterial contamination still remains a longstanding problem in transfusion medicine. Platelets are especially affected because of favorable conditions for bacterial growth like the storage temperature and the biological composition of platelet concentrates.

\section{Risks}

The risks of bacterial contamination are 50-250 times higher than the combined risks of HIV, HBV, HCV and HTLV. ${ }^{1}$ Bacterial contamination occurs in about $1 / 3000$ platelet units and lead to sepsis in 1 out of 6 contaminated products. ${ }^{2}$ A bacterial load of $>102 \mathrm{CFU} /$ $\mathrm{ml}$ is considered as serious risk. ${ }^{3}$

\section{Microbiology}

Different mechanisms may lead to platelet contamination the major being inadequate disinfection of venopuncture site. Other can be asymptomatic bacteremia in donor and contaminated blood sampling kit or anticoagulant. Gram positive bacteria like Staphylococcus aureus, coagulase negative Staphylococci, viridans group Streptococci, Bacillus spp., Corynebacteria as well as anaerobic diptheroid and Propionibacterium acnes are the common pathogens. ${ }^{4}$

\section{Diagnostic approach}

Within 90minutes after transfusion was started if symptoms appears like fever $\geq 39^{\circ} \mathrm{C}$, shivering, tachycardia, changes in systolic pressure we can clinically suspect bacterial sepsis. Severity of the clinical manifestations related to contaminated platelet units are determined by quantitative/qualitative parameters like number of $\mathrm{CFU}$ infused, type of bacteria, rate of proliferation and latency phase. ${ }^{5}$ But the amount of bacteria transfused is not always correlated with symptoms, particularly in the case of neutropenic or febrile patients under antibiotic therapy, among whom the signs of sepsis may be missed. There is greater benefit to prevent the risk of bacterial infection by strictly watching the quality of the blood product rather than evaluating its clinical consequences.

Swirling phenomenon assessment in platelet concentrate and microscopic assessment of blood and its components (Gram staining, fluorescence microscopy) and measuring glucose concentration, $\mathrm{pCO}_{2}, \mathrm{pO}_{2}$ and $\mathrm{pH}$ have shown to have low sensitivity. BacT/Alert (BioMerieux) and eBDS (Pall) are used currently to detect bacterial contamination. BacT/ALERT system is a colorimetric blood culture method based on the detection of carbon dioxide produced by proliferating micro organisms which allows the detection of both aerobic and anaerobic bacteria as well as yeasts and fungus. Pall eBDS is an enhanced bacterial detection method based on the measurement of oxygen consumption by organisms and is highly specific. The limitation of the Pall eBDS detection system is failure to detect anaerobic bacteria.

In order to provide more rapid, sensitive and highly specific results, molecular technologies, based on the detection of ribosomal RNA of a
Volume 3 Issue 3 - 2016

\author{
Subhashish Das, Argha Baruah \\ Department of Pathology, Sri Devaraj URS Medical College, \\ India
}

Correspondence: Subhashish Das, Professor and Incharge of Blood Ban, Department of Pathology, Sri Devaraj URS Medical College, Tamaka, Kolar, Karnataka 563I0I, India, Email daspathology@gmail.com

Received: September 03, 2016 | Published: December I5, 2016

wide variety of bacteria in a platelet contaminated sample containing $1-10 \mathrm{CFU} / \mathrm{mL}$, have also been evaluated. ${ }^{6}$ Even if molecular based technologies represent a high potential for bacterial detection, their applicability in the context of detection of bacteria in platelet concentrates has not yet been demonstrated. Also their use is limited by the cost, complexity of use and also due to the limited availability of bacterial-derived nucleic acid amplification reagents. ${ }^{7}$ Platelet PGD is another test and is rapid, qualitative immunoassay for the detection of aerobic and anaerobic bacteria.

\section{Newer ideas}

Pathogen reduction technologies allow inactivation of viruses and bacteria in contaminated platelet concentrates by inhibiting proliferation. Two methods are currently employed for platelet inactivation -psoralen and riboflavin-based. Psoralen method by interacting with nucleic acids modify genomic DNA in leukocytes, leading to the inactivation of T lymphocytes with more efficacy than gamma irradiation. The great sensitivity of T lymphocytes to psoralen suggests this method may prevent leukocyte-mediated adverse immune reactions associated with platelets transfusion such as transfusion-associated graft-versus-host disease and platelets-related febrile non-hemolytic transfusion reaction. ${ }^{8}$

Riboflavin interacts with nucleic acids after exposure to UV light, causing irreversible damage to DNA and RNA. In contrast to amotosalen, the removal of residual riboflavin metabolites is not necessary at the end of the procedure. ${ }^{9}$ Another inactivation method, which is based on the microbiocidal and virucidal properties of the short-wave ultraviolet light alone is under development. New inactivation method, which is based on the microbiocidal and virucidal properties of the short-wave ultraviolet light alone (200$280 \mathrm{~nm}$ ) is under development which inactivates pathogens mainly by its direct interaction with nucleic acids. ${ }^{10}$ Many detection technologies are under development like microcalorimetry, real-time polymerase chain reaction (PCR), microbial spore's biosensors, flow cytometry, detection of peptidoglycan, or monitoring bacterial response.

\section{Conclusion}

Each institution should establish its own measures to prevent or minimize the potential for contamination of platelet concentrates. The bacterial transmission still represents a threat in transfusion medicine. 
Pathogen inactivation technologies will constitute the next revolution in the field of transfusion medicine.

\section{Acknowledgements}

None.

\section{Conflict of interest}

The author declares no conflict of interest.

\section{References}

1. Blajchman MA, Beckers EA, Dickmeiss E, et al. Bacterial detection of platelets: Current problems and possible resolutions. Transfus Med Rev. 2005;19(4):259-272.

2. Hillyer CD, Josephson CD, Blajchman MA, et al. Bacterial contamination of blood components: Risks, strategies, and regulation: Joint ASH and AABB educational session in transfusion medicine. Hematology Am Soc Hematol Educ Program. 2003;575-589.

3. Morel P, Deschaseaux M, Bertrand X, et al. Transfusion-transmitted bacterial infection: Residual risk and perspectives of prevention. Transfus Clin Biol. 2003;10(3):192-200.
4. Palavecino E, Yomtovian R. Risk and prevention of transfusion-related sepsis. Curr Opin Hematol. 2003;10(6):434-139.

5. Hillyer CD, Josephson CD, Blajchman MA, et al. Bacterial contamination of blood components: risks, strategies, and regulation: joint ASH and $\mathrm{AABB}$ educational session in transfusion medicine. Hematology Am Soc Hematol Educ Program. 2003;575-589.

6. Wagner SJ. Transfusion-transmitted bacterial infection: risks, sources and interventions. Vox Sang. 2004;86(3):157-163.

7. Dreier J, Stormer M, Kleesiek K. Real-time polymerase chain reaction in transfusion medicine: applications for detection of bacterial contamination in blood products. Transfus Med Rev. 2007;21(3):237254.

8. Grass JA, Hei DJ, Metchette K, et al. Inactivation of leukocytes in platelet concentrates by photochemical treatment with psoralen plus UVA. Blood. 1998;91(6):2180-2188.

9. Joshi PC. Comparison of the DNA-damaging property of photo sensitised riboflavin via singlet oxygen $\left(1 \mathrm{O}_{2}\right)$ and superoxide radical $\mathrm{O}_{2}$ mechanisms. Toxicol Lett. 1985;26(2-3):211-217.

10. Mohr H, Steil L, Gravemann U, et al. A novel approach to pathogen reduction in platelet concentrates using short-wave ultraviolet light. Transfusion. 2009;49(12):2612-2629. 